\title{
La virtud en la formación médica en el Perú
}

REV EXP MED $2021 ; 7(1)$. Enero - Marzo

\author{
Virtue in medical education in Perú.
}

\author{
Sheyla Paola Montaño-Santa-Cruz 1,a, Cesar Ñique-Carbajal 1,b
}

\section{Sr. Editor:}

En nuestro país se han reportado faltas éticas como mala praxis en la labor médica, lo que nos obliga a mejorar la calidad de un sistema de salud precario, mediante el análisis reflexivo sobre los aspectos formativos del médico, el cual no solo debe enfocarse en la generación de profesionales que traten de construir códigos de conducta en base al rigorismo de cumplir el deber por cumplir (deontológico), sino incorporando y propiciando la práctica de la ética como una cultura de vida a nivel individual con repercusión social (1).

La virtud según Aristóteles es un hábito electivo regulado por la razón, es la forma como un hombre llega a ser prudente. Entre los modelos éticos, la ética de la virtud proporcionaría las cualidades necesarias para una vida humana bien lograda en sociedad o en su labor profesional, por ejemplo, como médicos. Para Sócrates a través de la virtud se puede alcanzar la felicidad y para Platón esta felicidad se logra mediante el conocimiento y la práctica constante de virtudes como: sabiduría, coraje, templanza y justicia. En el Perú el ente encargado de verificar las competencias profesionales es el Colegio Médico del Perú, a través del Código de Ética y Deontología, se pueden reconocer los deberes, derechos y valores con el que debería actuar el medico de manera justa ante la sociedad a la cual se debe; si su desempeño profesional es contrario al código de ética esto conllevaría a una sanción u amonestación que incluye retirar las licencias para ejercer la profesión en nuestro medio ${ }^{(2,3)}$.

Al respecto un estudio realizado entre los años 1991 - 2005 sobre los factores mas frecuentes asociados a sanciones éticas, se encontró que el $55 \%$ de los casos fue por mala atención o relación con los pacientes, el otorgamiento irregular de certificados médicos con un $11.5 \%$, delitos como el homicidio culposo en un $10.5 \%$, la realización de procedimientos sin la evaluación del consentimiento informado en un $9.1 \%$ de los casos; este último factor fue vinculado con médicos de especialidad quirúrgica de Gineco-obstetricia, quienes recibieron un tipo de sanción leve, y para el caso de los médicos generales que también cometieron este tipo de falta fueron sancionados con categorías de mayor envergadura. Evidentemente ante este panorama según la evidencia es importante gestar y promocionar médicos con actividad bifocal, capaces de cuidar a sus pacientes con competencia técnica-científica, pero con responsabilidad ética ${ }^{(3,4)}$.

Incorporar la practica virtud en el desarrollo de la competencia profesional del médico es muy importante ya que esto es inherente a su labor y desempeño profesional; siendo lo propio del buen hacer, en este caso del buen hacer como médico. Ante ello, no se pretende vincular la revaloración de la virtud con el tipo de número y de asignaturas en una malla médica, sino el recordar la importancia y el análisis de vivir la virtud per se en los escenarios tanto académicos y hospitalarios. En las facultades de medicina en el Perú, se registraron tres aspectos en su formación científica, ética y humanitaria; logrando desenvolver al estudiante dentro de una cultura ética más humana, es decir; evitando el incremento de costos en la atención médica o generando limitaciones en los recursos disponibles en el ejercicio profesional (2,5).

\footnotetext{
1 Universidad Señor de Sipán, Chiclayo, Perú

a Estudiante de medicina humana

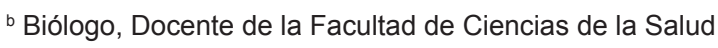


En este sentido, es importante crear ambientes académicos donde se viva la virtud en el logro de las competencias actitudinales para el buen hacer del futuro profesional médico; mediante la ética de la virtud se refuerza la formación académica, se forja el carácter y se brinda calidez humana. Así mismo se puede dar solución de conflictos médicos a través del trabajo en equipo, con compromiso en la interacción docente y estudiante, aprendiendo en este proceso a distinguir lo bueno de lo malo y elegir lo correcto, actuando así con justa consideración. Vivir la virtud en la práctica profesional genera satisfacción personal y es satisfactorio del buen hacer para los demás, requiriendo para ellos el ejemplo de docentes médicos, mediante su vida ayude a fomentar este modelo $(2,5)$.

Conflictos de interés: Los autores declaran no tener conflictos de interés.

Fuentes de financiamiento: Autofinanciado

\section{REFERENCIAS BIBLIOGRÁFICAS}

1. Vera O. Aspectos éticos y legales en el acto médico. Rev Med La Paz, [Internet] Julio - Diciembre 2013 [citado 20 Feb 2021]; 19(2). Disponible en: http://www.scielo.org.bo/pdf/rmcmlp/v19n2/v19n2_a10.pdf

2. Polo Santillán M. Repensando las virtudes desde la hermenéutica analógica crítica. Letras (Lima), [Internet] 2017 [citado 25 Feb 2021]; 88(128), 186-206. Disponible en: http://www.scielo.org.pe/scielo.php?script=sci_arttext\&pid=S2071-50722017000200010

3. Colegio Médico del Perú. Código de Ética y Deontología. Modificado mediante Resolución Nº 088 - CN - CMP - 2020

4. Cardenas M. Procesos ético - disciplinarios y judiciales derivados del acto médico en el Perú. [Tesis Doctoral]. Lima. Facultad de Medicina. Universidad Nacional Mayor de San Marcos, [Internet] 2017 [citado 20 Feb 2021] Disponible en: http://cybertesis.unmsm.edu.pe/bitstream/handle/20.500.12672/7127/Cardenas_dm.pdf?sequence=1\&isAllowed=y

5. Diaz E, Heredia M, Ñique C. Reflexión sobre los valores éticos en la formación del médico en el Perú. Rev. cuerpo méd. HNAAA [Internet] 2019 [citado 21 Feb 2021]; 12(3). Disponible en: https://cmhnaaa.org.pe/ojs/index. $\mathrm{php} / \mathrm{rcmhnaaa/article/view/540/288}$ 